\title{
INTRODUÇÃO: CONSUMINDO MEMÓRIAS DE CASA NA CONSTRUÇAO DO PRESENTE E IMAGINANDO O FUTURO ${ }^{1}$
}

Monica Janowski ${ }^{2}$

\section{Comida e migração}

Agora é amplamente reconhecido na Antropologia de que os estudos das 'práticas alimentares' são importante para o entendimento de como as pessoas constroem a noção de quem são (1). As maneiras pelas quais os alimentos desempenham papel no contexto da migração não receberam tanta atenção até agora (embora veja Kershen, 2002). No entanto, existem bons motivos para sugerir que a compreensão dos processos de migração em si pode se beneficiar se examinados por meio das lentes da comida e da bebida; que indiscutivelmente desempenham um papel central na construção da identidade no contexto da migração tanto em nível individual como coletivo. Para os migrantes, comida e bebida são fundamentais na manutenção dos laços familiares, sociais e culturais, na construção de novos agrupamentos e na criação de divisões, tanto entre os imigrantes e os grupos 'anfitriões' e dentro de um grupo de migrantes. Essa convicção que me levou em companhia de Parvathi Raman a organizar um workshop sobre 'Comida e Migração' na Escola de Estudos Orientais e Africanos da Universidade de Londres, em janeiro de 2009. Esse workshop resultou em duas coleções de artigos: esta coleção e outra que formou uma edição especial da revista Food, Culture and Society publicada em junho de 2011.

Os documentos apresentados nesse workshop sublinharam o fato de que os alimentos não apenas refletem mudança e continuidade; são usados deliberadamente por migrantes para fazer declarações de continuidade ou mudança. Ao fazer tais declarações, indivíduos e grupos não se baseiam apenas em noções que trouxeram com eles sobre alimentação adequada, relações de oferta e compartilhamento, sobre os elementos apropriados e a estrutura dos eventos de comer e beber; também se baseiam no que encontram no novo ambiente em que eles vivem, para alterar as relações dentro do grupo de imigrantes e também para gerar novas relações fora do grupo. Eles podem se apegar à existência de práticas alimentares e as relações que as acompanham para resistir à mudança. Podem recorrer a práticas alimentares

\footnotetext{
${ }^{1}$ Publicado originalmente com o título Introduction Consuming Memories of Home in Constructing the Present and imagining the Future; In: Food and Foodways: Explorations in the History and culture of Human Nourishment, v. 20, n. 3-4, p. 175-186, 2012.

${ }^{2}$ Escola de Estudos Orientais e Africanos, Universidade de Londres, Londres, Reino Unido.
} 
para fazer declarações religiosas ou políticas sobre identidade, por exemplo, por meio do consumo de carne halal ou kosher ou para gerar uma identidade alicerçada na atividade econômica, como, por exemplo, a criação de restaurantes.

As práticas alimentares em si não são normalmente - talvez nunca sejam - estáticas. No entanto, com a migração, a 'ideia' de uma via alimentar pode se tornar 'fossilizada' e se tornar um importante marcador de identidade. Uma alimentação pode assumir uma função simbólica - não apenas para imigrantes, mas também, até certo ponto, para grupos de acolhimento e membros de outros grupos de imigrantes. Para um grupo de imigrantes, isso pode levar ao consumo de refeições, rituais, representações culturais, religiosas ou identidade de grupo em certas ocasiões. Para grupos de acolhimento e outros imigrantes, também, alimentos e refeições "marcantes" derivados do repertório de um grupo de imigrantes podem, em seu consumo em casa ou em outro lugar, desempenhar um papel na construção de sua própria identidade sincrética. Refeições rituais de comida e bebida "marcadoras" consumidas por migrantes são vistas como trazidas da 'pátria'; mas elas podem, de fato, ser significativamente diferentes das formas como os alimentos e as bebidas são consumidos 'em casa'. A mudança ocorre de forma muito diferente 'em casa' e entre os migrantes: 'volta para casa'. Mudanças nos hábitos alimentares - até mesmo mudanças em alimentos e refeições rituais - são mais prováveis de ocorrer sem que sejam visíveis ou sendo vistos como um problema; entre os migrantes, por outro lado, é provável muito mais que ocorram mudanças profundas nos padrões de consumo diário. Ao mesmo tempo, muitas vezes, há maior preocupação na manutenção da continuidade de práticas alimentares, particularmente em relação a refeições rituais e alimentos "marcadores", porque do interesse em manter a continuidade da identidade - em um contexto onde mudança não pode, de fato, ser evitada, mas pode ser mitigada, com alimentos usados como um meio de tentar alcançar isso.

\section{Migrando, comendo e lembrando}

Essa coleção enfoca particularmente o papel da memória. Se a pessoa permanece em um lugar ou muda para um novo, a comida, devido a sua natureza sensível e seu potencial para atuar como um poderoso mnemônico, tem um enorme potencial como um meio de lembrar o passado, seja deliberadamente ou não (SUTTON, 2001). Isso é evidenciado pela popularidade das memórias baseadas em alimentos, como aquele publicado por Fisher (1943). Esses têm um amplo apelo, provavelmente porque eles evocam e/ou contrastam com memórias alimentares do próprio leitor. A comida tem um papel como parte das histórias 
individuais, com memórias da infância e eventos-chave, muitas vezes fortemente associados a certos alimentos e métodos de preparação; e em um âmbito de grupo, uma vez que a comida não é incomumente associada a memórias de fazer parte de um grupo que produz, processa, cozinha e / ou consome alimentos juntos. Comida, então, tem a capacidade de 'codificar' a memória. Também pode ser usado para 'decodificar' memórias (MINTZ, 1997, p. 96); é um meio de acessar novamente o que é lembrado como aconteceu no passado, se esta é uma representação precisa do passado, uma projeção desejada do passado ou colorida por memórias negativas.

No entanto, como os outros tipos de memórias, as memórias alimentares não devem ser vistas como relatos diretos do que realmente aconteceu. Histórias contadas sobre o passado, para si mesmo ou publicamente, são tingidas de emoções complexas. Isto deve ser lembrado que a ambivalência e dissonância são fundamentais para memória, embora isso não seja frequentemente explorado na discussão antropológica (apesar veja SMITH, 2004). O próprio conceito de 'memória' é complexo, refletindo como faz as memórias de indivíduos, grupos e sociedades mais amplas e incorporando a ampla gama de significados que pode denotar, mesmo em relação com uma pessoa. Apesar disso, como Holtzman (2006) apontou, estudos sobre o papel dos alimentos, mesmo dentro da Antropologia, tenderam a se concentrar nas formas como os processos se desdobram ao longo do tempo, em vez do que nas complexidades das maneiras como as pessoas se lembram do passado (MINTZ, 1985; CWIERTKA, 2000). Isso tende a implicar que a memória é um dispositivo para (mais ou menos) lembrar com precisão o que "realmente" aconteceu, ao invés de algo que é profundamente manipulado por sentimentos sobre o presente.

O potencial inerente de complexidade e ambivalência ligado aos alimentos é provável que apareça no contexto de mudança, particularmente onde a mudança é traumática. A migração é, em certo sentido, sempre traumática, portanto, deve-se esperar um "trabalho" criativo particularmente intenso de "lembrança" que ocorre com a migração. Um ponto importante a ter em mente é que, embora 'memórias' do passado reflitam sentimentos sobre o presente, eles também são usados para criar o futuro. $\mathrm{O}$ alimento é um grão importante para a criação do futuro. Isto fornece o potencial para ser usado de maneiras criativas, com base nas memórias do passado para construir não só o presente, mas também o futuro.

Certos alimentos, em particular, possuem este potencial, carregando especial, status indexical, com particular ressonância para aspectos culturais, sociais, religiosos e/ou razões cosmológicas. Isso pode ser devido à cosmologia central de um alimento e seu papel simbólico, por exemplo, dentro de uma sociedade agrícola organizada em torno de sua 
produção; ou pode ser porque ele foi associado a grupos dominantes ou lugares estrangeiros "exóticos" (Douglas, 1975; Smith, 1984; Mintz, 1985; Camporesi, 1989; Turino, 1999; Stewart, 2003; Janowski, 2007). No contexto da diáspora e migração, o potencial detido por tais alimentos centrais torna-se particularmente marcante e importante. Quando as pessoas se mudam para um novo lugar, esses alimentos tendem a assumir uma posição particularmente poderosa na reestruturação da vida. Eles são fundamentais para contar histórias sobre identidade e pertencimento, com base no que se acredita ser compartilhado ou não compartilhado do 'terra natal'. Essas histórias são fundadas em memórias, reais ou imaginárias, de vidas vividas naquela pátria. A identidade e o pertencimento suscitados por meio de tais histórias são vividos por meio da preparação e do consumo de alimentos 'marcadores' e rituais entre os migrantes em uma nova casa.

Todas as contribuições para essa coleção mostram como as 'memórias' da comida são usadas criativamente para construir um senso de identidade no presente que é dependente de esforços conscientes para alcançar o passado, esforços esses que são, ao mesmo tempo, inextricavelmente envolvidos em uma construção de identidade no presente e no futuro. Walker olha para os migrantes de uma das ilhas comorianas, Ngazidja, na França e em Zanzibar, e nas diferentes formas de alimentação nas quais a comida é usada nesses dois contextos para fazer afirmações sobre ser 'comoriano'. Em Zanzibar, isso inclui uma declaração pública sobre ser diferente de outros Zanzibaris e, também, dentro da comunidade comoriana, sobre ser verdadeiramente Comorian; na França, inclui uma declaração pública sobre ser diferente, mas também significa estender a mão e dar as boas-vindas ao mundo francês em geral. Rowe explora as múltiplas camadas de identidade geradas por meio dos alimentos por imigrantes libaneses para os EUA, que usam as práticas alimentares para manter e projetar uma identidade libanesa e uma identidade "americana branca". Rosales examina as formas como os alimentos são utilizados por pessoas de origem goesa que migraram de Goa a Moçambique há muitos anos e depois a Portugal, para projetar certos tipos de relações entre eles e entre eles próprios e os portugueses em Moçambique, de forma que continuam a ter significado em Portugal. Gasparetti examina a interação complexa entre as maneiras como os alimentos são usados entre os migrantes senegaleses para Torino para gerar diferença entre eles - e entre eles e outros migrantes, mas, ao mesmo tempo, uma identidade comum vis-à-vis o mundo italiano. Ele mantém limites e permite que esses limites sejam ultrapassados. Marte mostra como os alimentos são usados por mulheres da República Dominicana morando na cidade de Nova York para enfatizar seu próprio senso de autoestima, suas redes sociais e seu próprio senso de identidade como mulheres e como dominicanas 
vivendo em Nova Iorque. Coakley mostra como em Cork a comida evoca emoções profundas entre os migrantes poloneses, ambos mantendo uma noção de onde vêm, mas também servindo para 'movê-los' para uma nova identidade em seus novos lares. Na minha própria contribuição sobre as experiências de mulheres deportadas do que era o leste da Polônia para o Cazaquistão e a Sibéria com a eclosão da Segunda Guerra Mundial, mostro como a comida foi fundamental para manter e remodelar um senso de 'polonês', por meio de sua longa 'odisséia' pela Ásia Central, Oriente Médio, África e no Reino Unido.

\section{Atos criativos de lembrança}

O processo de criar essas histórias e as viver durante a preparação e consumo de certos alimentos e refeições de certa maneira e com certas pessoas envolve atos altamente criativos, que reconstroem o passado a fim de criar o presente e o futuro. A comida é a base para criativas interpretações do passado e projeções para o futuro com base nestas interpretações. Isso ecoa o conceito de Anderson de 'comunidade imaginada' (ANDERSON, 1991); os migrantes se veem como vindos de tal comunidade e a criando ou como criando uma nova comunidade que tem continuidade com a comunidade na pátria. Também ecoa a noção de Hobsbawn (1983) de tradição inventada.

Não há dúvida de que a nostalgia é uma emoção e atitude central para práticas alimentares entre os migrantes, com alimentos usados para evocar uma pátria passada, como Ray, por exemplo, mostra entre os americanos bengalis (RAY, 2004). Contudo, o anseio que é experimentado pelos migrantes e especialmente por seus descendentes, muitas vezes, pode ser o que Appadurai (1996) descreveu como nostalgia de 'poltrona': eles podem se lembrar de eventos que não aconteceram com eles pessoalmente e que podem nunca ter acontecido. Os migrantes podem amar memórias pessoais ou de grupo de práticas alimentares que são o tema de icônicas narrativas que simbolizam história e identidade, mas que podem não refletir a realidade. Isso é ilustrado em minha contribuição para esta coleção; algumas das mulheres que foram deportadas eram tão jovens que não podiam ter memórias do lugar onde nasceram ou mesmo de grande parte da 'odisseia' por que passaram, mas elas se baseiam em memórias de outros para construir uma "memória" própria. Também é ilustrado na contribuição de Rosales; os Goenses que ela discute não me lembram de Goa, de onde seus ancestrais vieram gerações atrás, mas carregam histórias de Goa, impulsionadas pelo consumo da comida goesa, que são, sem dúvida, em grande medida, míticas. As histórias que os migrantes contam sobre 
o passado, alimentadas pela comida, podem, de fato, ser usadas para gerar um senso de identidade que dificilmente existe além da mesa, como Buckser (1999) apontou entre os judeus na Dinamarca. A mesa pode ser o último bastião de um desaparecimento, embora emocionalmente carregada, identidade.

'Memórias' compartilhadas de práticas alimentares icônicas podem ser o assunto de construção criativa de grupos sociais em uma nova casa. Eles podem servir para ajudar a unir ou separar pessoas, agrupando as pessoas como sendo de uma 'pátria' compartilhada que não teriam, naquela 'pátria', se visto como sendo do mesmo grupo. Eles podem unir pessoas de diferentes classes, castas ou clãs, origens, ou pessoas de lugares amplamente espalhados. Eles também podem, é claro, servir para separar pessoas que estariam mais próximas se tivessem permanecido na pátria'. Assim, as pessoas de Ngazidja consideram-se comorianas, como Walker mostra em sua contribuição para esta coleção e expressa isso por meio de alimentos que são marcados como tal; como Rosales mostra em sua contribuição, as pessoas de diferentes castas e classes veem-se a si mesmas compartilhando uma identidade goesa comum longe de Goa (embora também mantenham identidades de castas distintas), e expressar isso por meio de certos alimentos que são considerados 'Goeses' embora sejam muito diferentes de tudo o que se come em Goa; e, como Gasparetti mostra em sua contribuição, senegaleses de diferentes partes do país compartilham uma identidade comum por meio da ingestão de alimentos marcados como 'senegaleses', que são, em outro nível, marcados como 'africanos' quando compartilhados com os marroquinos e conferem identidade comum vis-à-vis o mundo italiano.

Alimentos indicativos ou "marcadores" são usados para evocar uma pátria e os acessando, preparando-os e os consumindo, são percebidos como fundamentais para manter uma identidade enraizada naquela pátria. Às vezes, esses alimentos podem ser aqueles usados no contexto da própria pátria para sublinhar e projetar identidade nacional (por exemplo, ver OHNUKI-TIERNEY, 1993; MURCOTT, 1996; BELLASCO, SCRANTON, 2002) e isso é aproveitado pelos migrantes na construção de seu próprio senso de identidade compartilhada fundada na nostalgia do passado. Contudo, alimentos indexical no contexto da migração podem ser diferentes em maneiras sutis ou significativas de quem está na terra natal. Eles podem ser alimentos que são altamente valorizados em casa e, portanto, são adotados como parte de uma exibição de afluência na migração, como vemos no artigo de Walker que se concentra no alimento indexical ntsambu, a semente fermentada de uma cicadácea, que é vista como um marcador de ser comoriano entre as pessoas de Ngazidja que vivem em Zanzibar. No entanto, tem um cheiro forte que é apreciado em Ngazidja, mas não por migrantes para 
Zanzibar e se torna mais palatável por ser vendida em variedades que não têm cheiro. Alimentos indicativos também podem ser alimentos diários em casa, como mostro em minha contribuição. Nesse caso, são feitos com ingredientes diferentes dos mesmos alimentos atualmente consumidos na Polônia e consumidos pela primeira geração migrantes antes de deixarem sua terra natal.

\section{Lembrança de gênero}

A maioria dos estudos sobre práticas alimentares no contexto da migração lida com memórias de mulheres, por exemplo por Innes (2001), Meyers (2001), Counihan (2002, 2004). Isso, às vezes, está ligado a uma análise de práticas alimentares como uma valorização de contribuição das mulheres para a construção de uma nova sociedade (COUNIHAN, 2002), algumas coisas que Marte traz em sua contribuição. O papel dos homens nas práticas alimentares, inclusive no contexto da migração, tem recebido menos atenção, embora tenham aparecido alguns estudos sobre os papéis masculinos na construção da memória em relação à comida (EVES, 1996). As mulheres geralmente lidam com o processo final na cadeia de produção de alimentos: cozinhar. No entanto, é importante notar que os homens desempenham um papel importante na alimentação; não só eles são responsáveis por obter e produzir muitos alimentos, mas em contextos rituais, muitas vezes por preparar comida, especialmente carne, como Walker destaca em sua contribuição para esta coleção (e vejam-se KAHN, 1988; JANOWSKI, 1995).

Embora o papel das mulheres como cozinheiras todos os dias possa ser visto em alguns sentidos como trabalho enfadonho, também lhes dá uma boa dose de poder. Quem preparou a comida que uma pessoa come e com quem se come é sempre profundamente importante (CARSTEN, 1997; JANOWSKI, 2007) e isso tem uma particular ressonância no contexto da migração por causa das mudanças muito rápidas que geralmente ocorreram na estrutura social e a importância da prática alimentar na construção de novos relacionamentos entre pessoas e/ou manter relacionamentos com a pátria. No contexto da migração, a forma como o controle sobre os alimentos confere poder pode se tornar particularmente evidente. Todos os migrantes provavelmente se sentirão relativamente impotentes; mas os homens, porque normalmente não são responsáveis por cozinhar, muitas vezes são particularmente impotentes nessa área. Eles não podem se abastecer com a comida que eles querem comer, mas dependem das mulheres para fazer isso. Porque comida é central para manter a identidade, esta é uma questão de preocupação explícita e torna visível o que é menos visível 
na pátria: a dependência dos homens em relação às mulheres para a identidade cultural e social. Gasparetti, em sua contribuição, mostra como as mulheres senegalesas obtêm um senso definido de poder social e político de fornecer comida senegalesa a outros e a si próprias. Eles são não só conseguem ganhar dinheiro com isso, mas também disciplinam os jovens senegaleses, recusando-lhes comida se se comportarem mal. Marte, na sua contribuição, mostra como as mulheres dominicanas na cidade de Nova Iorque derivam um sentido de valor político e social e, portanto, um senso de poder sobre seu próprio destino e dos outros, ao cozinhar para si e para sua família.

\section{'Limbo migrantes', memória e comida}

A memória pode se tornar um ato particularmente criativo entre aqueles que deixaram sua pátria com filhos pequenos ou descendentes de migrantes. Tal indivíduos são suscetíveis de serem criados com histórias sobre o 'país antigo', a terra natal, e são solicitados a seguir padrões culturais e sociais, incluindo práticas alimentares, que dizem derivar dessa pátria. No entanto, eles não têm memória própria daquele lugar em que se veem como enraizados. Eles estão presos em uma espécie de limbo, ocupando um espaço entre uma identidade e outra. Mesmo que tenham nascido no país em que eles estão vivendo, eles podem se sentir, até certo ponto, como se fossem, eles mesmos, migrantes, como se parte deles estivesse presa em outro lugar - em um lugar de que eles não têm memória própria. Eles são o que pode ser descrito como 'migrantes do limbo'.

Todos os migrantes se encontram em uma situação em que quase sempre há muitas rotas possíveis para o futuro à sua disposição, muitas identidades diferentes e combinações de identidades às quais podem aspirar e pelos quais podem trabalhar para construir. Paradoxalmente, dada sua identidade intermediária, isto é particularmente verdadeiro para 'migrantes limbo' que, porque se mudaram muito jovens ou nasceram no novo país, podem adotar e adaptar novas formas mais facilmente. Em relação à alimentação, seus paladares são menos formados por distintos alimentos e estão mais abertos a novos sabores e combinações de alimentos. No entanto, alguns são, por razões sociais, mais restritos do que outros; e os indivíduos variam individualmente em seu desejo e capacidade de assumir a oportunidade de usar alimentos, entre outros meios, para construir um futuro distinto para eles mesmos. Alguns dependem muito mais de uma identidade dependente de 'memórias' herdadas dos mais velhos na construção de um futuro; outros rejeitam essas 'memórias' e estendem a mão para o 
novo país em busca de material com base no qual visam construir uma nova identidade. As práticas alimentares são uma parte central das escolhas disponíveis para eles.

Rosales mostra em sua contribuição como alguns 'migrantes do limbo' - os goenses, agora residentes em Portugal, - dependem fortemente de certas 'memórias herdadas' enraizados em alimentos para sua identidade. Por causa da profunda sensualidade da comida e, devido a isso, portanto, evocam memórias pessoais da infância; a comida, sem dúvida, tem a capacidade de fazer os migrantes do limbo sentirem que eles estavam evocando memórias de eventos alimentares equivalentes na terra natal, vivida por seus pais, avós ou bisavós. As memórias de outros podem, como eu descrevo entre os poloneses "migrantes do limbo" nascidos no Reino Unido, ser tratadas como se fossem memórias pessoais; o limite entre o que é realmente lembrado e o que foi transplantado de outra pessoa fica confuso e as memórias transplantadas das mentes de outros podem ser tratadas como suas próprias memórias. A consciência de que isso está acontecendo ligado, consciente ou subconsciente, pode causar ansiedade e acentuar o desejo para reafirmar e relatar o que são memórias inventadas ou transplantadas.

Essas memórias reconstituídas e reencenadas emprestadas de outros não são sempre bem-vindas por todos os 'migrantes limbo', no entanto; alguns jovens da primeira geração, os migrantes de segunda e terceira geração rejeitam as práticas alimentares associadas com a terra natal de onde vieram seus pais e avós. O desejo de comer os alimentos da nova pátria é pelo menos em parte, baseado em uma mudança na inclinação gustativa; com a exposição aos hábitos alimentares de uma sociedade anfitriã no contexto da escola e de socialização mais ampla, aqueles que crescem naquela sociedade anfitriã apega-se aos novos alimentos que encontram. No entanto, a rejeição dos hábitos alimentares dos pais e avós migrantes também pode estar ligada a um desejo de rejeitar parte ou toda a identidade enraizada no 'antigo país'. As contribuições de Marte e Gasparetti, assim como as minhas, mostram o processo de se tornar apegado a uma nova identidade e aos hábitos alimentares locais entre migrantes de segunda geração. Entre senegaleses, poloneses e dominicanos, nós vemos como os filhos de cozinheiras podem relutar em comer alimentos da pátria cozinhados por sua mãe. Gasparetti lembra que para os senegaleses jovens, isso é enquadrado como uma recusa explícita da identidade senegalesa. 


\section{Conclusão: o alimento do passado como combustível para o futuro}

As contribuições para esta coleção demonstram diferentes maneiras que, por meio da comida, a corda bamba em direção ao futuro pode ser percorrida por migrantes, usando materiais do passado e do presente. A comida é importante material desse tipo. Por causa de sua força sensual e emocional, tem uma habilidade particularmente poderosa de relembrar o passado; e quando introduzida na construção do futuro tem uma potente capacidade de manipular sentimentos e comportamento. Por causa de seu significado e status sensorial complexos, os alimentos têm grande potencial para refletir - e gerar - mudanças. Podem ser usados de maneiras altamente criativas para manipular memórias. Nós olhamos para exemplos de maneiras pelas quais pode ser usado para imaginar o passado, para projetar este para o presente e para criar o futuro. Certos alimentos indexados em particular podem ser usados dessas maneiras criativas, como vimos.

O gênero, é claro, aparece em todos os papéis desta coleção, mostrando o quão importante é a comida na construção das relações entre os homens e mulheres, bem como na construção e projeção do papel das mulheres em particular. No contexto da migração, vimos como a relação de dependência que os homens têm em relação às mulheres para o alimento se torna particularmente notável.

Todos os migrantes estão em processo de construção de uma nova identidade para eles mesmos como indivíduos. Neste processo, sua participação em grupos que, oriundos de sua terra natal, desempenham um papel importante e isso se expressa por meio da escolha dos alimentos que eles fazem. No entanto, quanto mais jovens eles são quando se movem, quanto mais opções eles têm de novas identidades e novas práticas alimentares associadas com estas e, ao mesmo tempo, menos memória eles têm da pátria de onde vieram. Com a segunda geração de migrantes, nascida no novo país, isso se torna particularmente verdadeiro. Portanto, descrevi esses mais jovens da primeira e da segunda geração de migrantes e da subsequente, que se identificam como oriundos da pátria de seus pais, como 'migrantes do limbo': nem uma coisa nem outra.

Provavelmente, pode ser razoavelmente afirmado que a segunda e as subsequentes gerações nunca tentam reviver completamente um passado imaginado nem rejeitar completamente esse passado. Eles estão no negócio de construir o novo, identidades híbridas. Mesmo se eles se descrevam como 'poloneses' ou 'goianos', o que isso significa não é o mesmo para eles e para os poloneses que vivem na Polônia ou Goanos que vivem em Goa. Eles veem sua própria identidade como tendo sido alterada, tornando-se hibridizada com as 
culturas hospedeiras. É gerada uma nova identidade 'polonesa britânica' ou 'portuguesa goesa', que eles veem como algo distinto, ao mesmo tempo, desejando também fundamentá-la no 'país antigo'.

O alimento é combustível: não apenas para o nosso eu biológico, mas também para o nosso eu social, como seres humanos que vivem em grupos que comem juntos de maneira que explícita e implicitamente fazem declarações sobre identidade e pertencimento. Como combustível social, permite que indivíduos e grupos se movam para o futuro. No contexto da migração, este se torna um processo particularmente ativo e necessário. Recordações sobre os alimentos são mobilizadas e manipuladas, atraídas e alimentadas, em um processo ativo que não faz apenas uma declaração sobre a afiliação a pessoas e grupos individuais, mas faz parte de um grupo ativo e, às vezes, de um altamente aspiracional processo de mudança para novos espaços sociais, de classe e étnicos. A comida fornece um espaço sensível e social para aproveitar o passado para construir o presente e imaginar o futuro.

\section{Notas}

(1). A relação dos autores que escreveram sobre isso inclui Lévi-Strauss, 1970 [1964]; Douglas, 1971, 1984; Murcott 1983; Harris, 1985; Manderson, 1986; Bourdieu, 1986 [1979]; Harris e Ross, 1987; Kerr e Charles, 1988; Fiddes, 1991; Camporesi, 1993; Caplan, 1994; Lupton, 1996; Mintz, 1996; Bell e Valentine, 1997; Caplan, 1997; Carsten 1997; Counihan e van Esterik, 1997; van Esterik e Coynihan, 1997; Gabaccia, 1998; Murcott, 1998; Pillsbury, 1998; Atkins e Bowler, 2001; Dietler e Hayden, 2001; Mintz e Du Bois, 2002; Bryant, DeWalt et al., 2003; Mason, 2004; Conquhoun, 2007; Janowski e Kerlogue, 2007.

(2). Food, Culture and Society, v. 14, n. 2, jun. 2011. A coleção é apresentada por Harry West (2011) e inclui artigos de Emma-Jayne Abbots (2011), Nicola Frost (2011), Ray Krishnendu (2011), Anne Meneley (2011), Parvathi Raman (2011) e Lidia Marte (2011).

\section{Referências Bibliográficas}

ABBOTS, E. J. It Doesn't Taste as Good from the Pet Shop: Guinea Pig Consumption and the Performance of Transnational Kin and Class Relations in Highland Ecuador and New York City. Food, Culture and Society, v.14, n. 2, p. 205-223.

ANDERSON, B. Imagined communities: reflections on the origin and spread of nationalism. London: Verso, 1991. 
APPADURAI, A. Modernity at Large: Cultural Dimensions of Globalization. Minneapolis: University of Minnesota Press, 1996.

ATKINS, P.; BOWLER, I. (Eds.). Food in Society: Economy, Culture, Geography. London: Arnold, 2001.

BELL, D.; VALENTINE, G. Consuming Geographies: We are what we eat. London: Routledge, 1997.

BELLASCO, S.; SCRANTON, P. (Eds.). 2002. Food Nation: Selling Taste in Consumer Societies. London: Routledge, 2002.

BOURDIEU, P. 1986, 1979. Distinction: A Social Critique of the Judgement of Taste.

London: Routledge and Kegan Paul, 1986 [1979].

BRYANT, C., DEWALT, K. et al. The Cultural Feast: An Introduction to Food and Society. Belmont, CA: Thomas Wadsworth, 2003.

BUCKSER, A. Keeping kosher: eating and social identity among the Jews of Denmark. Ethnology, n. 38, p. 191-209, 1999.

CAMPORESI, P. Bread of Dreams: Food and Fantasy in Early Modern Europe. Cambridge, UK: Polity Press, 1989.

. The Magic Harvest: Food, Folklore and Society. Cambridge: Polity Press, 1993.

CAPLAN, P. Feasts, Fasts, Famine: Food for Thought. Oxford/Providence: Berg, 1994. (Ed.). Food, Health and Identity. London: Routledge, 1997

CARSTEN, J. The Heat of the Hearth: The Process of Kinship in a Malay Fishing Community. Oxford: Clarendon Press, 1997.

CONQUHOUN, K. Taste: The Story of Britain through its Cooking. London: Bloomsbury, 2007.

COUNIHAN, C. Around the Tuscan Table. New York and London: Routledge, 2004. (Ed.). Food in the USA: A Reader. London and New York: Routledge, 2002. Food as woman's voice in the San Luis Valley of Colorado. Food in the USA. New York: Routledge, 2002. p. 295-304.

COUNIHAN, C.; P. VAN ESTERIK, P. (Eds.). Food and Culture: a Reader. London: Routledge, 1997.

CWIERTKA, K. From Yokohama to Amsterdam: meidi-ya and dietary change in modern Japan. Japanstudien, n.12, p. 45-63, 2000. 
DIETLER, M.; HAYDEN, B. (Eds.). Feasts: Archaeological and Ethnographic Perspectives on Food, Politics and Power. Washington, D.C.: Smithsonian Institution Press, 2001.

DOUGLAS, M. Deciphering a Meal. Daedalus, v.101, n. 1, p. 61-81, 1971.

(Ed.). Food in the Social Order: Studies of Food and Festivities in Three American Communities. New York: Russell Sage Foundation, 1984.

The Sociology of Bread: Social, Nutritional and Agricultural Aspects of Wheaten Bread. London: Applied Science Publishers Ltd, 1975.

EVES, R. Memories of things passed: memory, body and the politics of feasting in New Ireland. Oceania, v. 66, n. 4, p. 266-77, 1996.

FIDDES, N. Meat: A Natural Symbol. London: Routledge, 1991.

FISHER, M. F. K. The Gastronomical Me. New York: Duell, Sloan and Pierce, 1943.

FROST, N. Green Curry: Politics and Place-Making on Brick Lane. Food, Culture and Society, v.14, n. 2, p. 225-242, 2011.

GABACCIA, D. R. We are what we eat: ethnic food and the making of Americans. Harvard: Harvard University Press, 1998.

HARRIS, M. The Abominable Pig. In: Good to Eat: Riddles of Food and Culture. New York: Routledge, 1985.

HARRIS, M.; ROSS, E. (Eds.). Food and Evolution. Philadelphia, PA: Temple University Press, 1987.

HOBSBAWM, E. 1983. Introduction: inventing traditions. In: HOBSBAWM, E.; RANGER, T. The Invention of Tradition. Cambridge: Cambridge University Press, 1983. p. 1-14.

HOLTZMAN, J. Food and Memory. Annual Review of Anthropology, n.35, p. 361-78, 2006.

INNES, S. (Ed.). Cooking Lessons. Lanham, MD: Rowman and Littlefield, 2001.

JANOWSKI, M. Feeding the right food: the flow of life and the construction of kinship in Southeast Asia. In: JANOWSKI, M.; KERLOGUE, F. Kinship and Food in Southeast Asia. Copenhagen: NIAS Press, 2007.

The hearth-group, the conjugal couple and the symbolism of the rice meal among the Kelabit of Sarawak. In: CARSTEN, J.; HUGH-JONES, S. About the House: Levi-Strauss and Beyond. Cambridge, UK: Cambridge University Press, 1995. p. 84-104.

JANOWSKI, M.; F. KERLOGUE, F. (Eds.). Kinship and Food in Southeast Asia. Copenhagen: RoutledgeCurzon, 2007.

KAHN, M. Men are Taro (They cannot be Rice): Political Aspects of Food Choices in Wamira, Papua New Guinea. Food and Foodways, n. 3, p. 41-57, 1988.

KERR, M.; CHARLES, N. Women, Food and Families. Manchester: Manchester University Press, 1988. 
KERSHEN, A. J. (Ed.). Food in the Migrant Experience. Aldershot: Ashgate, 2002.

KRISHNENDU, R. Dreams of Pakistani Grill and Vada Pao in Manhattan: Re-Inscribing the Immigrant Body in Metropolitan Discussions of Taste. Food, Culture and Society, v. 14, n. 2, p. 243-273, 2011.

LÉVI-STRAUSS, C. The Raw and the Cooked. New York: Harper Torchbooks, 1970 [1964].

LUPTON, D. Food, the Body and the Self. London: Sage Publications, 1966.

MARTE, L. Afro-Diasporic Seasonings: Food Routes and Dominican Place-Making in New York City. Food, Culture and Society, v.14, n. 2, p. 84-104, 2011.

MANDERSON, L. Shared Wealth and Symbol: Food, Culture and Society in Oceania and Southeast Asia. Cambridge: Cambridge University Press, 1986.

MASON, L. Food Culture in Great Britain. Westport, CT: Greenwood Press, 2004.

MENELEY, A. Blood, Sweat and Tears in a Bottle Palestinian Extra-Virgin Olive Oil. Food, Culture and Society, v.14, n. 2, p. 275-292, 2011.

MEYERS, M. A Bite off Mama's Plate: Mothers' and Daughters' Connections through Food. New York: Bergin and Garvey, 2001.

MINTZ, S. Sweetness and Power: The Place of Sugar in Modern History. New York: Viking Penguin, 1985.

. Tasting Food, Tasting Freedom. Boston: Beacon Press, 1996.

. Time, Sugar and Sweetness. In: COUNIHAN, C. Food and Culture: a Reader. London: Routledge, 1997. p. 357-369.

MINTZ, S. W.; DU BOIS, C. M. The Anthropology of Food and Eating. Annual Review of Anthropology, n. 31, p. 99-119, 2002.

MURCOTT, A. Food as an expression of identity. In: GUSTAFFSON, S.; LEWIN, L. The Future of the National State: Essays on Cultural Pluralism and Political Integration. Stockholm: Nerenius and Santerus, 1996. p. 49-77.

. The Nation's Diet. The Social Science of Food Choice. London and New York: Longman, 1998. . (Ed.). The Sociology of Food and Eating. Ashgate, Kent, UK: Aldershot, 1983.

OHNUKI-TIERNEY, E. Rice as self: Japanese identities through time. Princeton: Princeton University Press, 1993.

PILLSBURY, R. No Foreign Food: The American Diet in Time and Place. Colorado and Oxford: Westview Press, 1998.

RAMAN, P. Me in Place, and the Place in Me. A Migrant's Tale of Food, Home and Belonging. Food, Culture and Society, v. 14, n. 2, p. 165-180, 2011. 
RAY, K. The Migrant's Table: Meals and Memories in Bengali-American Households. Philadelphia: Temple University Press, 2004.

SMITH, A. Heteroglossia, "common sense" and social memory. American Ethnologist, v. 31, n. 2, p. 251-69, 2004.

SMITH, R. E. F. Bread and Salt: a social and economic history of food and drink in Russia. Cambridge: Cambridge University Press, 1984.

STEWART, S. On Longing: Narratives of the Miniature, the Gigantic, the Souvenir, the Collection. Durham: Duke University Press, 2003.

SUTTON, D. E. Remembrance of Repasts: An Anthropology of Food and Memory. Oxford: Berg, 2001.

TURINO, T. Signs of Identity, Imagination and Experience: A Piercian Semiotic Theory of Music. Champaign: University of Illinois Press, 1999.

VAN ESTERIK, P.; COYNIHAN, C. (Eds.). Food and Culture: A Reader. London: Routledge, 1997.

WEST, H. From the Editors. Food, Culture and Society, v. 14, n. 2, p. 163-164, 2011. 